seem esoteric and perhaps one that should not even be asked when a modern "seamless service" is provided between hospital and community.

Consider a district general hospital (DGH) serving the local community. The advent of Trust status has divided this previously functional unit into three Trusts, each managed separately. Can patients, detained under Section 3 in the psychiatric Trust, no longer visit the hospital canteen opposite, nor the WRVS cafe next door? A visit for morning coffee would have to be preceded by an expensive and time consuming Section 117 aftercare meeting. (Code of Practice, 1993 Chapters 20 and 27).

Consider another DGH some miles along the motorway. This hospital has the same managers as the previously mentioned psychiatric unit so is therefore "the same hospital" (MHAC Practice Note 3, 1994). Is a patient under Section 3, or Section 5 (2), transferring between the widely spread wings of this single hospital, in any way "in the hospital grounds"?

Consider a hospital unit of four wards. Two upstairs wards are part of the psychiatric DGH Trust, two are not. How far down the stairs can a physiotherapist take a Section 3 patient, for mobility exercises? To where do these wards' grounds extend?

Successive Biennial reports issued by the MHAC offer relevant commentaries on current issues and helpful advice. Unfortunately, the dividing and recombining of clinical services, under separate Trusts, complicate service delivery and make implementation of the reports' advice more difficult. We must be clear about where the hospital and its grounds terminate because of increasing accountability and litigation. As Coiera (1996) warns, "While patients may be motivated to seek out the most recent literature for their condition and can invest considerable efforts in that search, most practising doctors cannot".

COIERA, E. (1996) The Internet's challenge to health care provision. British Medical Journal, 312, 3-4.

M. T. Malcolm, Clatterbridge Hospital, Clatterbridge Road, Bebington, Wirral L63 4JY

\section{The moral status of suicide}

Sir: Oyebode's article (Psychiatric Bulletin, 20, 85-89) was both stimulating and interesting. I would like to state some aspects of Buddhist philosophy relating to life, death and suicide. In Buddhist philosophy, referring to Gautama Siddatha and his teachings that go back more than 2500 years, life is sacred not because it was "God" who created it. It is sacred because life is the culmination of all the "right forces" happening in the "right manner" and at the "right times". The other associated notion is of the present life as just one in a series of many. The cause and effect - do good and prosper and do evil and suffer, is somewhat of a theme here. Kill yourself once, leads on to kill yourself again and again in the lives to come. This teaching bears no resemblance to the idea that 'God' is the creator. The 'crime' of taking one's own life is with oneself - nobody else is involved. It is not against the state, humanity or even religion. Life is not an end in itself - it is a means towards the end, Nirvana. The concept that 'one is the master of one's own destiny', appears to have a powerful impact on those who practise Buddhist philosophy.

F. K. M. ZAW, Birmingham Children's Hospital Trust, Ladywood, Birmingham B16 8ET

\section{Whose journal is it anyway?}

Sir: Rather than stacking a journal unread on the shelf, can I remind readers of the possibility of donating journals and books to needy libraries overseas. Book Aid International support mainly African libraries. They are pleased to receive a few years' collection of a journal, or an annual commitment as a delayed subscription. Transport can often be arranged via the local rotary club. The address to contact is: Book Aid International, Tel: 0171733 3577; Fax: 0171 978 8006; Email: Hs@gn.apc.org.

A. GRAY, 42 Wyche Road, Malvern, Worcestershire WR14 4EG 